\title{
Genetic and environmental analysis of dystocia and stillbirths in draft horses
}

\author{
M. Sabbagh ${ }^{1}$, S. Danvy ${ }^{1}$ and A. Ricard ${ }^{1,2 \dagger}$ \\ ${ }^{1}$ Recherche et Innovation, IFCE, 61310 Exmes, France; ${ }^{2}$ UMR 1313, INRA, 78352 Jouy-en-Josas, France
}

(Received 22 April 2013; Accepted 11 October 2013; First published online 21 November 2013)

Genetic parameters and environmental factors were estimated for foaling ease (FE) and stillbirths (SBs) in four breeds of draft horses based on 11 229, 38 877, 35764 and 13274 FE and SB scores recorded between 1998 and 2010 for Ardennais (A), Breton $(B)$, Comtois (C) and Percheron (P), respectively. Incidences for the three FE categories were: easy or without help 91.0\% (A) to $95.4 \%(B)$, difficult $3.4 \%(B)$ to $7.1 \%(A)$ and intervention of a veterinarian $1.1 \%(B)$ to $1.9 \%(A)$. The frequency of $S B$ ranged between $5.4 \%$ (B) and 9.4\% (A). A multiple-trait threshold animal model was used that included the effects of sex of foal, region, month, year of foaling, combined maternal age and parity, direct genetic, maternal genetic and permanent environments. Estimates were obtained using Markov Chain Monte Carlo Gibbs sampling. The most unfavourable effect was first parity, which decreased the probability of easy foaling to $78.6 \%$ for $A$ and $88.3 \%$ for $B$. Interaction with age showed that the risk for first foaling for mares aged 3 years was higher than at 4 or 5 to 9 years. This was also observed for SB with an increased probability of $S B$ at first foaling of $17.9 \%$ (A) or $9.6 \%$ (B). The most unfavourable month was found to be the most frequent month for foaling (April) and not the most demanding months weather-wise (winter). For FE, direct heritabilities were $A 0.27(0.06), B 0.14$ (0.03), $C 0.18(0.03)$ and $P 0.18(0.04)$, and maternal heritabilities were $A 0.25(0.06), B 0.19(0.04), C 0.12(0.03)$ and $P 0.21(0.06)$. Genetic correlations between direct and maternal genetic effects were $A-0.29(0.14), B-0.39(0.12), C-0.09(0.14)$ and $P-0.54$ (0.17). For $S B$, direct heritabilities were $A 0.52(0.09), B 0.42(0.04), C 0.28(0.04)$ and $P 0.39(0.05)$, and maternal heritabilities were $A 0.25(0.05), B \quad 0.10(0.02), C 0.07(0.02)$ and $P 0.14(0.02)$. Genetic correlations between direct and maternal genetic effects were $A-0.85(0.06), B-0.63(0.06), C-0.64(0.11)$ and $P-0.69(0.06)$. Direct genetic correlations between $F E$ and $S B$ traits were $A 0.60(0.10), B 0.58(0.10), C 0.36(0.10)$ and $P 0.29(0.15)$. Maternal genetic correlations between FE and SB traits were $A 0.67$ (0.10), $B 0.47(0.13), C 0.28(0.15)$ and $P 0.39$ (0.15). These estimates are posterior means of the Gibbs samples and are within the upper limits of comparable results reported in cattle.

Keywords: dystocia, stillbirths, draft horse, genetic parameters, heritability

\section{Implications}

Dystocia is a significant cause of female and neonatal death in horse breeding (McCue and Ferris, 2012). Breeders are generally amateurs who are not interested in modern genetics. Fortunately, French breeding associations have recorded data on foaling ease and stillbirths in four breeds of draft horses for over 10 years. By studying gestations in interbred mares, it was first evidenced in 1938 and recently confirmed that the size of the mare regulated foal size (Walton and Hammond, 1938; Allen et al., 2002). As the biology of gestation may differ between horses and cattle, this original genetic study has proven its usefulness. Knowing

\footnotetext{
${ }^{\dagger}$ E-mail: anne.ricard@toulouse.inra.fr
}

heritability and genetic correlation between the capacities for a stallion to produce foals easy to birth and mares easy to foal, breeding values are now available.

\section{Introduction}

In horses, the relative importance of heredity and the environment in the intrauterine development of foal and foaling difficulties of mares is a long-standing issue, which was first reported in 1937 by Walton and Hammond in a paper describing spectacular crosses between Shetland ponies and Shire horses. Their results suggested that foetal growth was controlled by the mare, hence concealing many genetic differences in the foal. Since then, the components of dystocia and stillbirths (SBs; gestation length, position and 
posture of the foetus, size of mare and foal, placenta characteristics and duration of labour) have been studied to elucidate the underlying mechanisms and to prevent their occurrence (Ginther and Williams, 1996; Allen et al., 2002; Allen et al., 2007; Langlois et al., 2012; McCue and Ferris, 2012; Squires et al., 2013). These studies were for the most part conducted on warmblood horses (thoroughbred, quarter horses) where both the foal and the mare are worth enough to call for adequate care at foaling. In France, the problem of foaling difficulties was raised by breeders of heavy horses. They had been recording foaling scores and data on SB for more than 10 years. Their objective was to improve their breeds by selection on these characteristics. Recently, statistical tools have become available for estimating both genetic parameters for complex threshold traits (such as scores) and direct and maternal effects (such as the biology of dystocia) in animal models. These Markov Chain Monte Carlo (MCMC) and Gibbs sampling methods (Lopez de Maturana et al., 2007; Legarra et al., 2011) avoid the biased inference of restricted maximum likelihood (REML) methodology for binary traits (Moreno et al., 1997).

The aim of this paper was to estimate genetic parameters for dystocia or, a contrario foaling ease (FE) and SBs, in breeds of draft horses.

\section{Material and methods}

\section{Data}

French birth registration forms for draft horses include, since 1998, a score to record the conditions of foaling. In this study, we focused on the main breeds: Breton (B), Comtois (C), Percheron $(\mathrm{P})$ and a fourth category designated Ardennais (A) including Ardennais, Auxois, Trait du Nord breeds between which the genetic distance is very small and that can mate together (Leroy et al., 2009). Only pure bred births from 1998 to 2010 were considered. Scores for FE were assigned by the breeder: 'without help', 'easy', 'difficult' and 'intervention of the veterinarian'. It was found to be difficult, both for breeders and during data analysis, to clearly distinguish between 'without help' and 'easy'. The data for these two categories were therefore grouped during analysis and we used three ordered categories: $1=$ 'without help or easy', $2=$ 'difficult', $3=$ 'intervention of the veterinarian'. Data were missing about foaling difficulty on the registration forms in $21 \%$ to $30 \%$ of cases, but without any particular distribution depending on the region, maternal age, sex of foal or sires. Cases of observed dystocia were excluded if the sex of the foal was missing (1\%). Unfortunately the scores for these excluded observations were high with $31 \%$ of the births recorded as 'difficult', instead of $3 \%$ to $7 \%$ in the data retained for analysis. But as the sex ratio remained close to $50 \%$ in the analysed data, we expected the estimates not to be biased for the effects included in the model. SBs were defined as foals that were born dead and never showed a detectable heartbeat. The characteristics of the data sets are provided in Table 1. All available pedigree data for mares and foals were used in the analysis. Therefore, between 17231
Table 1 Total number of births, analysed births and distribution of scores for FE and SBs in the four breeds

\begin{tabular}{lrrrr}
\hline \hline & \multicolumn{4}{c}{ Breed } \\
\cline { 2 - 5 } Item & 14435 & 49655 & 51693 & 17847 \\
\cline { 2 - 5 } & Ardennais & Breton & Comtois & Percheron \\
\hline Number of births & 3029 & 10369 & 15598 & 4459 \\
$\quad$ With missing score & 180 & 409 & 877 & 114 \\
$\quad$ With missing sex & 11229 & 38877 & 35764 & 13274 \\
Number of births analysed & 77.8 & 78.3 & 69.2 & 74.4 \\
\% Births analysed & & & & \\
Distribution of scores of FE & 91.0 & 95.4 & 94.7 & 93.3 \\
$\quad$ Easy or without help (\%) & 7.1 & 3.4 & 4.1 & 5.0 \\
$\quad$ Difficult (\%) & 1.9 & 1.1 & 1.3 & 1.7 \\
$\quad$ With veterinarian (\%) & 9.4 & 5.4 & 8.3 & 7.3 \\
SBs (\%) & \multicolumn{4}{c}{} \\
\hline \hline
\end{tabular}

$\mathrm{FE}=$ foaling ease; $\mathrm{SB}=$ stillbirth.

Table 2 Number of horses in pedigrees used in the analysis in the four breeds

\begin{tabular}{lcccc}
\hline \hline & \multicolumn{4}{c}{ Breed } \\
\cline { 2 - 5 } Number of horses & Ardennais & Breton & Comtois & Percheron \\
\hline Mares of foals & 4039 & 12873 & 12876 & 4927 \\
Sires of foals & 680 & 1483 & 1784 & 446 \\
Sires of mares & 878 & 1558 & 1628 & 594 \\
Total & 17231 & 54885 & 54932 & 19085 \\
\hline \hline
\end{tabular}

and 54932 animals were included in the analysis depending on the breeds (Table 2). The mean number of births per mare ranged from $2.7(\mathrm{P})$ to $3.0(\mathrm{~B})$ and the mean number of births per sire ranged from $16.5(\mathrm{~A})$ to $29.8(\mathrm{P})$.

\section{Method}

A threshold mixed model was assumed for each of the traits. This model (Sorensen and Gianola, 2002) considers one (for binary traits) or several thresholds (for polychotomous traits) and a liability that, over a given threshold, produces an observed phenotype. The liability follows a normal distribution and may be explained by a classical linear model. A multiple-trait threshold linear mixed model with three categories of observations for FE and two for SB was assumed. Each trait followed the same model:

$$
\mathbf{y}=\mathbf{X b}+\mathbf{W a}+\mathbf{Z u}+\mathbf{Z p}+\mathbf{e},
$$

where $\mathbf{y}$ is the vector of liability for $\mathrm{FE}$ or $\mathrm{SB}, \mathbf{b}$ the vector of fixed effects, a the vector of random direct additive genetic effects for the foal, $\mathbf{u}$ the vector of random maternal additive genetic effects for the mare, $\mathbf{p}$ the vector of random permanent environmental effects for all consecutive foalings of the mare, e the vector of residuals and $\mathbf{Z}, \mathbf{W}$ are incidence matrices. The distributions of vectors $\mathbf{a}, \mathbf{u}, \mathbf{p}$ and $\mathbf{e}$ were 
assumed normal with variance matrices:

$$
V\left[\begin{array}{c}
\mathrm{a}_{\mathrm{FE}} \\
\mathbf{u}_{\mathrm{FE}} \\
\mathrm{a}_{\mathrm{SB}} \\
\mathbf{u}_{\mathrm{SB}}
\end{array}\right]=\left[\begin{array}{cccc}
\sigma_{a_{\mathrm{FE}}}^{2} & \sigma_{a_{\mathrm{FE}} u_{\mathrm{FE}}} & \sigma_{a_{\mathrm{FE}} a_{\mathrm{SB}}} & \sigma_{a_{\mathrm{FE}} u_{S B}} \\
\sigma_{a_{\mathrm{FE}} u_{\mathrm{FE}}} & \sigma_{u_{\mathrm{FE}}}^{2} & \sigma_{u_{\mathrm{FE}} a_{S B}} & \sigma_{u_{\mathrm{FE}} u_{S B}} \\
\sigma_{a_{\mathrm{FE}} a_{S B}} & \sigma_{u_{\mathrm{FE}} a_{S B}} & \sigma_{a_{S B}}^{2} & \sigma_{a_{S B} u_{S B}} \\
\sigma_{a_{\mathrm{FE}} u_{S B}} & \sigma_{u_{\mathrm{FE}} u_{S B}} & \sigma_{a_{S B} u_{S B}} & \sigma_{u_{S B}}^{2}
\end{array}\right] \otimes A
$$

where $\mathbf{A}$ is the relationship matrix and

$$
\begin{aligned}
& V\left[\begin{array}{l}
\mathbf{p}_{\mathrm{FE}} \\
\mathbf{p}_{\mathrm{SB}}
\end{array}\right]=\left[\begin{array}{cc}
\sigma_{p_{\mathrm{FE}}}^{2} & \sigma_{p_{\mathrm{FE}} p_{\mathrm{SB}}} \\
\sigma_{p_{\mathrm{FE}} p_{\mathrm{SB}}} & \sigma_{p_{\mathrm{SB}}}^{2}
\end{array}\right] \otimes \mathbf{I}, \\
& V\left[\begin{array}{l}
\mathbf{e}_{\mathrm{FE}} \\
\mathbf{e}_{\mathrm{SB}}
\end{array}\right]=\left[\begin{array}{cc}
\sigma_{\mathrm{e}_{\mathrm{FE}}}^{2} & \sigma_{\mathrm{e}_{\mathrm{FE}} \mathrm{e}_{\mathrm{SB}}} \\
\sigma_{\mathrm{e}_{\mathrm{FE}} \mathrm{e}_{\mathrm{SB}}} & \sigma_{\mathrm{e}_{\mathrm{SB}}}^{2}
\end{array}\right] \otimes \mathbf{I}
\end{aligned}
$$

Fixed effects were: year of foaling (from 1998 to 2010), month of birth (January and February, March, May, June, July and after), region of foaling (six regions covering the traditional areas for each breed and five other large regions), sex of the foal (male, female), combined maternal age and parity (with $\mathrm{F}$ for first foaling, $\mathrm{D}$ for the second and third foaling and $M$ for further parities; the nine levels of this effect were: 3 years $F$, 4 years $F$, 4 years $D, 5$ to 9 years $F, 5$ to 9 years $D$, 5 to 9 years $M, 10$ years and more $F, 10$ years and more $D$, 10 years and more $M)$. In order to assure correct estimation of all effects, at least one FE score and SB score was observed for each level of each fixed effect.

For each trait, the following genetic parameters were defined (subscript omitted): the phenotypic variance was $\sigma_{y}^{2}=\sigma_{a}^{2}+\sigma_{u}^{2}+\sigma_{a u}+\sigma_{p}^{2}+\sigma_{e^{\prime}}^{2}$ the heritability of the direct effect was $h_{d}^{2}=\frac{\sigma_{a}^{2}}{\sigma_{y}^{2}}$ the heritability of the maternal effect was $h_{m}^{2}=\frac{\sigma_{u}^{2}}{\sigma_{y}^{2}}$ the genetic correlation between maternal and direct effects was $r_{a u}=\frac{\sigma_{a u}}{\sigma_{a} \sigma_{u}}$, the repeatability between two foalings of the same mare (assuming a different sire) was $r=\frac{\sigma_{p}^{2}+\frac{1}{4} \sigma_{a}^{2}+\sigma_{u}^{2}+\sigma_{a u}}{\sigma_{y}^{2}}$. The following parameters were defined between traits: the genetic correlation between direct

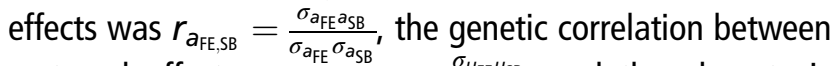
maternal effects was $r_{U_{\mathrm{FE}, S \mathrm{SB}}}=\frac{\sigma_{u_{\mathrm{FE}} u_{S B}}}{\sigma_{u_{\mathrm{FE}}} u_{\mathrm{SB}}}$ and the phenotypic correlation between $\mathrm{FE}$ and $\mathrm{SB}$ for the same foaling was

$r_{\mathrm{FE}, \mathrm{SB}}=\frac{\sigma_{a_{\mathrm{FE}} a_{\mathrm{SB}}}+\sigma_{u_{\mathrm{FE}} u_{\mathrm{SB}}}+\frac{1}{2}\left(\sigma_{a_{\mathrm{FE}} u_{\mathrm{SB}}}+\sigma_{u_{\mathrm{FE}} a_{\mathrm{SB}}}\right)+\sigma_{p_{\mathrm{FE}} p_{\mathrm{SB}}}+\sigma_{\mathrm{e}_{\mathrm{FE}} \mathrm{e}_{\mathrm{SB}}}}{\sigma_{y_{\mathrm{FE}}} \sigma_{y_{\mathrm{SB}}}}$

To estimate the different parameters, an MCMC Gibbs sampling was used with TM software (Legarra et al., 2011). For each population, Gibbs sampling was carried out through a unique chain of 100000 iterations, discarding the first 4000 iterations and retaining one every 20 samples.

Estimates for fixed and random effects were obtained for the liability variables. As the variance of each trait on this underlying scale is unidentifiable, we chose a phenotypic standard deviation of 1 and all the results in the figures are presented in this phenotypic standard deviation unit (s.d.). Knowing the estimated thresholds, an estimated probability to have the different scores for FE or SB for each combination of fixed and random effects could also be computed from the estimates of the effects and are provided in the text.
When discussing of a particular level of an effect, all other effects (fixed and random) except the one mentioned are the average of estimates according to their distribution in the actual data.

\section{Results}

\section{Estimates of environmental fixed effects}

The year of foaling showed erratic variations because of the particular environmental conditions of each year but with a clear decrease over time for $B$ (regression coefficient -0.03 s.d./year) and $P$ (regression coefficient -0.02 s.d./year), which suggested an improvement of the environmental conditions of foaling. The estimated probabilities for 'difficult' or 'with veterinarian' births decreased, respectively, from $6.2 \%$ before 2000 to $3.1 \%$ after 2008 for $B$, and from $8.1 \%$ to $5.3 \%$ for $\mathrm{P}$. The amplitude (maximum-minimum) of variations remained moderate for the other breeds, that is, $\sim 0.25$ s.d. Differences were observed for SB scores between the four first years recorded (from 1998 to 2001) and following years, but without improvement from then on. The more favourable months for foaling (Figure 1) were the rare early foalings (January and February, frequency of foalings 3\% (A) to $8 \%(B)$ ) or late foalings (June $4 \%$ (B) to $14 \%$ (A) and July to September, $2 \%$ (B) to $7 \%(\mathrm{~A}))$. The most unfavourable months were March to May with a maximum in April. There was no significant month effect for SB. Births of male foals were found to be more difficult with the same values for $B, C$ and $P$ (+0.17 s.d., +0.18 s.d., +0.16 s.d.) and +0.09 s.d. for $A$. This leads to an increase of the probability of difficult foalings or presence of a veterinarian of about 2 points. For $S B$, the unfavourable effect of males was higher for $C$ and $P$ $(+0.20$ s.d., +0.24 s.d.) than $A$ and $B$ (+0.14 s.d., +0.16 s.d.). Compared with female foals, the probability of SB was increased by 3 points for $\mathrm{C}$ and $\mathrm{P}$ for male foals. Foaling was

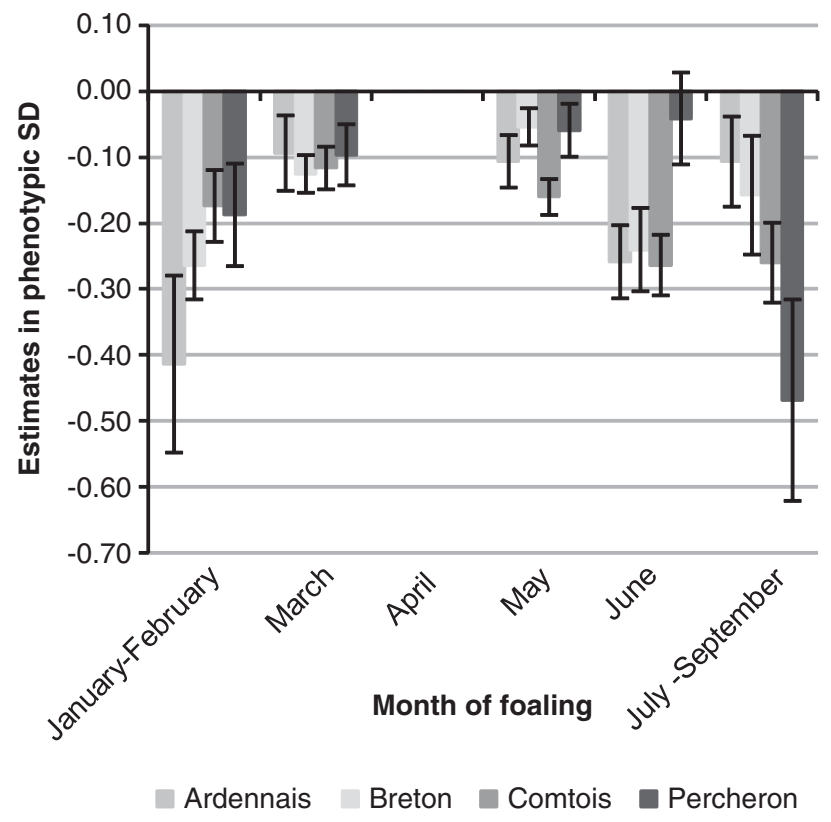

Figure 1 Effect of month of foaling on liability of foaling ease, expressed relative to April, for the four breeds. 

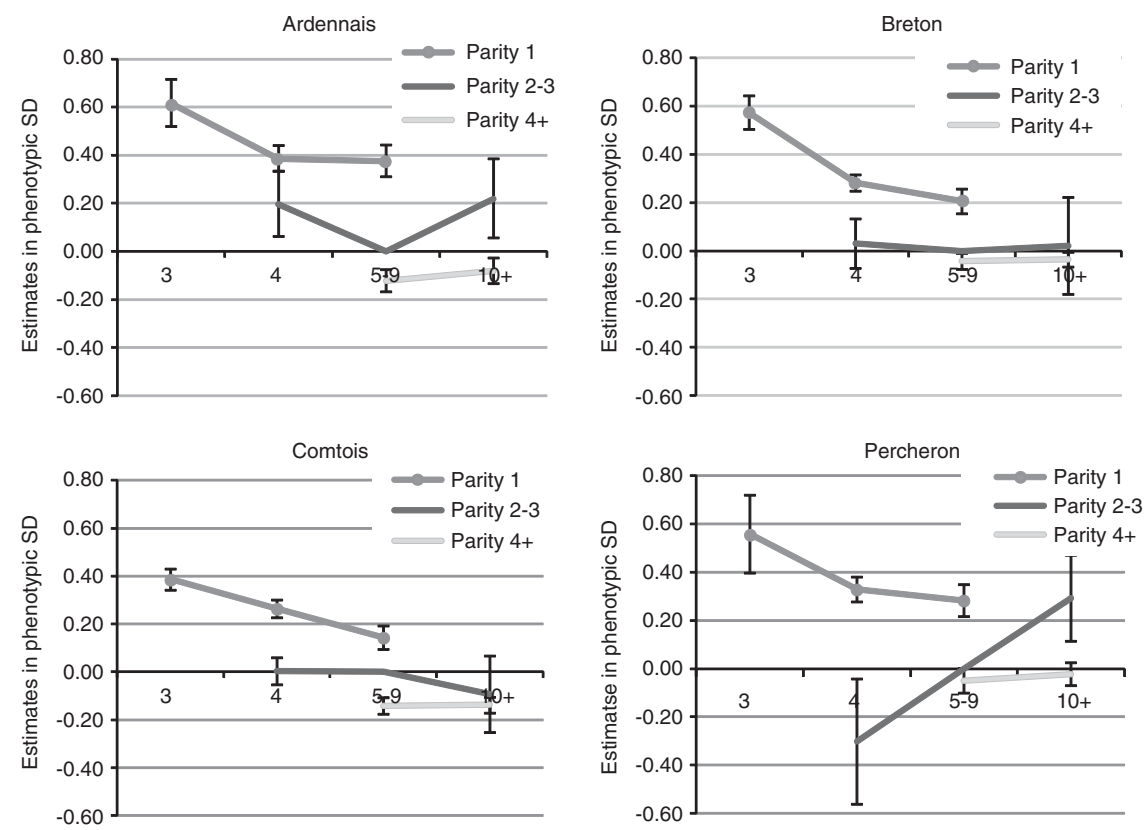

Figure 2 Effect of maternal age (in years) and parity on liability of foaling ease, expressed relative to parity 2 to 3 of mares aged 5 to 9 for the four breeds.

not found to be easier in the traditional geographical areas for the breeds, but only little variation was observed between regions and for the most part differences were not significant $(<0.20$ s.d.). Lower SB scores were observed for $B$ and $C$ in their traditional geographical areas. The fixed effect of maternal age and parity was the most important. Estimates are plotted in Figure 2 (except for first parity in mares aged 10 or more for whom standard errors were high due to the low number of cases). Foaling difficulties were higher both at first parity compared with second or third parity, and at second and third parity compared with following parities, with a 1.4- to 3.2-fold increase of the probability to have a FE score of 2 or 3 compared with the mean population. The age effect was important at age 3 years when the combination of first parity and age resulted in the highest risk. The differences between the age categories 5-9 years and 4 years were in favour of the older mares but were not significant in most cases. No significant differences were noted between mares aged 5-9 years and 10 years or more. Interactions were observed between age and parity effects; except for breed $C$. Foaling was more difficult if first parity occurs at age 5-9 years than at age 4 years for $A$, but the opposite was observed for $P$. The effect of maternal age and parity showed exactly the same pattern for SB.

\section{Genetic parameters}

Table 3 provides the estimated genetic parameters as posterior means of Gibbs sampler output and their standard deviations in parenthesis. For $\mathrm{FE}$, repeatability was homogeneous among breeds: from $0.26(\mathrm{P})$ to $0.32(\mathrm{~A})$. Direct heritability ranged from $0.14(B)$ to $0.27(A)$ and maternal heritability ranged from 0.12 (C) to 0.25 (A). Maternal heritability was lower than direct heritability for A and C, and higher for B and $P$. Genetic correlations were unfavourable for three of the breeds with values ranging from $-0.54(\mathrm{P})$ to $-0.29(\mathrm{~A})$, and almost neutral for $C(-0.09)$. Additionally, in order to test the robustness of these results, single trait analysis was performed with only two classes for foaling difficulties, that is, with by pooling the 'difficult' and 'with veterinarian' categories to increase the relative proportion of occurrences for this category in the data set. In this case, differences in estimates of genetic parameters were negligible $(<0.04$ point $)$ except for the genetic correlation between maternal and direct effect for $C(-0.25)$ associated with higher direct heritability (0.27).

For $S B$, repeatability was also homogeneous among breeds: from $0.10(C)$ to $0.14(A)$. Direct heritability of $S B$ ranged from $0.28(\mathrm{C})$ to $0.52(\mathrm{~A})$ and was higher than for $\mathrm{FE}$. Maternal heritability ranged from 0.07 (C) to $0.25(\mathrm{~A})$, and was both lower than maternal heritability for $\mathrm{FE}$ and direct heritability in all breeds. Genetic correlations were very unfavourable for all breeds and ranged from -0.63 (B) to -0.85 (A). The correlations between the two traits, FE and $S B$, were always positive and strong whatever the direct or maternal genetic effects especially for $A$ and $B$, with a similar phenotypic correlation in all breeds of $\sim 0.60$.

\section{Discussion}

The data included in the present study were sufficiently consistent and unselected to be used for genetic analysis. We failed to understand the causes of environmental improvement for $\mathrm{FE}$ for $\mathrm{B}$ and $\mathrm{P}$ with time (year effect) and change of the interpretation of scoring with time cannot be entirely excluded. In the same way, differences observed for SB in the four first years without improvement from then on, may be due to the way that observations are recorded (choice between SB and early mortality of a live foal). The estimates 
Sabbagh, Danvy and Ricard

Table 3 Genetic parameters of foaling ease in four breeds of draft horses (s.d. in brackets)

\begin{tabular}{|c|c|c|c|c|}
\hline \multirow[b]{2}{*}{ Traits and parameters } & \multicolumn{4}{|c|}{ Breed } \\
\hline & Ardennais & Breton & Comtois & Percheron \\
\hline \multicolumn{5}{|l|}{ Foaling ease } \\
\hline Direct heritability & $0.27(0.06)$ & $0.14(0.03)$ & $0.18(0.03)$ & $0.18(0.04)$ \\
\hline Maternal heritability & $0.25(0.06)$ & $0.19(0.04)$ & $0.12(0.03)$ & $0.21(0.06)$ \\
\hline Genetic correlation & $-0.29(0.14)$ & $-0.39(0.12)$ & $-0.09(0.14)$ & $-0.54(0.17)$ \\
\hline Repeatability $^{1}$ & $0.32(0.03)$ & $0.29(0.02)$ & $0.27(0.02)$ & $0.26(0.03)$ \\
\hline \multicolumn{5}{|l|}{ Stillbirths } \\
\hline Direct heritability & $0.52(0.09)$ & $0.42(0.04)$ & $0.28(0.04)$ & $0.34(0.05)$ \\
\hline Maternal heritability & $0.25(0.05)$ & $0.10(0.02)$ & $0.07(0.02)$ & $0.14(0.02)$ \\
\hline Genetic correlation & $-0.85(0.06)$ & $-0.63(0.06)$ & $-0.64(0.11)$ & $-0.69(0.06)$ \\
\hline Repeatability ${ }^{1}$ & $0.14(0.02)$ & $0.14(0.02)$ & $0.10(0.01)$ & $0.11(0.02)$ \\
\hline \multicolumn{5}{|l|}{ Correlation between traits } \\
\hline Genetic direct & $0.60(0.10)$ & $0.58(0.10)$ & $0.36(0.10)$ & $0.29(0.15)$ \\
\hline Genetic maternal & $0.67(0.10)$ & $0.47(0.13)$ & $0.28(0.15)$ & $0.39(0.15)$ \\
\hline Phenotypic & $0.59(0.02)$ & $0.62(0.01)$ & $0.63(0.01)$ & $0.56(0.02)$ \\
\hline
\end{tabular}

${ }^{1}$ Correlation between foalings of the same mare assuming different sires.

of environmental effects obtained here show the importance of maternal age and parity. There is always a risk at first foaling, especially if the mare is aged 3 years, so it may be preferable to wait and breed older mares. Ageing did not affect either FE or SBs as the risk was identical for mares aged 5 to 9 years and 10 years or more. The negative effect associated with ageing probably appears later on in life, for very old mares, as culling is higher from age 16 years, although it is also linked to fertility. These results are not in agreement with Allen et al. (2007) who reported a lower percentage of pregnancies in which the foal was born dead for young ( 3 to 8 years) and maiden thoroughbred mares, although the differences were not significant. Squires et al. (2013) also reported significantly lower dystocia (8.5\%) for maiden mares compared with multiparous mares $(14.2 \%$ for foaling mares and $12.7 \%$ for barren mares), again in thoroughbreds. Our results were comparable to those reported by Langlois et al. (2012) when they analysed gestation losses (i.e. between diagnosis of gestation and birth). They observed that gestation losses were lowest in mares aged 7 to 10 years and that mares with a foal at foot had an advantage over other mares, confounding barren and maiden mares. However, their study included all gestation losses and not just SBs even though it was assumed that SBs represented most of losses (185 detailed gestations were observed in which a third of losses occurred during the 11 months).

The unfavourable effect of first parity on dystocia and SB is well established in both dairy cattle (Meyer et al., 2000; Meyer et al., 2001a; Meyer et al., 2001b; Luo et al., 2002; Steinbock et al., 2003; Steinbock et al., 2006; Lopez de Maturana et al., 2007) and beef cattle (Carnier et al., 2000; Phocas and Laloe, 2004). We can therefore conclude that heavy horses are closer to cattle in this respect than to warmblood horses, that is, for breeding and horse management techniques, or possible mix-up between the maternal age and parity reported.
The estimates of month effects could be used to provide helpful advice for breeders. The fact that foaling difficulties were higher during the most frequent months for foaling (compared with months when the weather conditions can be an issue as in the winter or summer) suggest that this is probably more because of the lack of time for watching over the mares during this busy period, and thus a higher FE score, than to climatic reasons. It should be noted that no month effect was observed for SB. No differences in the incidence of dystocia depending on the month of parturition were reported by Squires et al. (2013) and an increase of gestation losses was observed by Langlois et al. (2012) for mares that were bred during month of last mating. In dairy cattle, on the contrary, winter months are the less favourable (Steinbock et al., 2003; Eaglen and Bijma, 2009).

The aim of this study was to provide estimated breeding values (EBVs) for breeders in order to improve the populations and avoid matings that could put mare and foal at risk. Although these tools are commonly used in other species, they are still novel for horse breeders. The high heritabilities of the direct effect for SB were unexpected and suggest that this is the best trait to select on. However, because of the high negative genetic correlation between direct and maternal effects, the repeatability between foalings of the same mare remained low, and lower than for FE (mean of 0.12 for SB v. 0.28 for FE). The parameters for SB therefore seemed less reliable than those for FE. However, given the high genetic correlation between the two traits, a multipletrait model should benefit from observations on both FE and SB. EBVs for FE are now calculated and available for breed leaders and will be soon for SB. Two values are provided for sires when reliability is $>0.20$ : facility of foaling (maternal genetic value) and facility of birth (direct genetic value). Nevertheless, based on to the unfavourable genetic correlation between direct and maternal effects that we have evidenced in this study for $A, B$ and $P$, it will be difficult to select sires 
that will both contribute to improving the FE of the mares mated with them and the FE of their daughters. This might not be the case for $\mathrm{C}$ because a negative correlation was only found for this breed when the 'difficult' and 'with veterinarian' scores were considered together and because the heritability of SB was much lower. This could be explained by the smaller size and weight of this breed and suggests that these results should not be generalised to all non-hypermetric breeds including warmbloods.

Various differences were observed between the breeds in this analysis. For $\mathrm{FE}$, they are the same as those described by Langlois et al. (2012) for foetal losses. However, for SB they differ from those reported previously in $C$ and $P$ breeds (in this study we observed that SB was higher in $C$ than $P$, whereas in the previous report higher gestation losses were observed in P and Boulonnais than in C). This could be due to the differences in format and weight of the horses or to differences in breeding management. $\mathrm{P}$ is the heaviest and tallest breed (900 to $1000 \mathrm{~kg}, 1 \mathrm{~m} \mathrm{68}$ ); the other breeds are smaller (700 to $800 \mathrm{~kg}, 1 \mathrm{~m} 58$ to $1 \mathrm{~m} \mathrm{60}$ ). The age at first foaling is younger for $C$ (mean 4.2) and $B$ (mean 4.3) than for $A$ and $P$ (mean 4.6). This lower age at first foaling is due to $a$ higher number of foalings at 3 years for $C$ ( $27 \%$ compared with $3 \%$ to $9 \%$ in other breeds) and 4 years for B (70\% compared with $49 \%$ to $65 \%$ in other breeds). For $B$, foalings preferably occur at the beginning of the year (33\% before April compared with $14 \%$ to $25 \%$ for the other breeds). For $A$, foalings preferably occur late in the year $(21 \%$ after May compared with $6 \%$ to $13 \%$ in other breeds). The heaviest breed did not show the highest rate of foaling difficulties. Indeed these reached $9.0 \%$ in the most unfavourable case, that is, breed A, but only $6.7 \%$ in the heaviest breed P. This perhaps results from an adaptation in breeding practices: because the highest FE scores are observed in $P$ and $A$, breeders have, over the years, chosen to use older mares for first foalings than $C$ and $B$. This was highlighted in our analysis by the unfavourable interaction between age 3 and first parity compared with the effect of first parity at age 4 or 5 to 9 . For the month effect, all breeds showed a similar curve for FE with a maximum of births in April. The absence of a month effect on SB is also common to all breeds even if the number of births per month varied between breeds. This reinforces the stability of our results in spite of the low occurrence of FE and SB. Only breed A, with their late foalings from June to September, has taken advantage of favourable effects.

No references could be found in the literature on genetic parameters for dystocia in horse breeding. In dairy cattle, the heritability of the direct effect for calving ease (CE) ranged from 0.01 with raw data to 0.19 with a threshold model, and the heritability of the maternal effect ranged from 0.02 with a threshold model to 0.14 with raw data (Luo et al., 2002; Steinbock et al., 2003; Wiggans et al., 2003; Hansen et al., 2004; Jamrozik et al., 2005; Steinbock et al., 2006; Lopez de Maturana et al., 2007, 2009a and 2009b; Eaglen and Bijma, 2009; Johanson et al., 2011; Eaglen et al., 2012). Appreciably higher estimates were obtained in beef cattle (Varona et al., 1999;
Carnier et al., 2000; Phocas and Laloe, 2003, 2004) with direct heritability within the range 0.09 to 0.27 , maternal heritability within the range 0.06 to 0.18 and genetic correlation within the range -0.19 to -0.55 . The most recent references used, as in our analysis, a threshold animal model and obtained heritability in the upper range for dairy cattle: 0.11 and 0.05 to 0.14 for direct and maternal effects, respectively (Johanson et al., 2011; Eaglen et al., 2012). Typically the direct heritability estimate was twice the magnitude of the maternal heritability estimate. It is common for genetic correlations between direct and maternal effects to be negative but they are often moderate and sometimes positive (Luo et al., 2002; Hansen et al., 2004), although the most recent studies using the threshold animal model reported more negative estimates $(-0.37$ to -0.67$)$. For SBs, genetic parameters are of the same magnitude (Steinbock et al., 2003; Hansen et al., 2004; Jamrozik et al., 2005; Steinbock et al., 2006; Lopez de Maturana et al., 2009b; Johanson et al., 2011; Eaglen et al., 2012) with a very low heritability ( 0.00 to 0.15$)$ but always a high genetic correlation between SB and CE (0.39 to 0.83). Compared with these results, our estimates are quite high for $\mathrm{FE}$ and very high for SB. The trait seemed to be distributed identically in the two species. The frequency of CE is very similar, considering only difficult calvings and those with veterinarian assistance: from $3 \%$ to $~ 8 \%$, and up to $14 \%$ for first calving in the previous listed references (except for the specialised Italian Piedmontese beef cattle breed in Carnier et al., 2000). The frequency of SB is also very similar from $3.1 \%$ to $13.1 \%$. As in our study, differences between low scores (easy or easy with moderate assistance) depended on the data and were not as relevant as the threshold for difficulties. Hence, the differences of the estimates for genetic parameters do not depend on differences of incidence of the trait between horses and cattle. Nevertheless, horse breeds are not managed in the same way as cattle: the proportion of first parity in our data $(20 \%)$ was low compared with that for dairy cattle (often more than $50 \%$ ), the number of parities for a given animal was higher (mean 3.8 for $\mathrm{C}$ to 4.2 for $\mathrm{A}$ ) and the lifespan was also longer in horses (mean age 7.9 for $B$ to 8.5 for A). Therefore, based on differences in biology, management, maternal age and parity, the trait may well be different. This is also supported by the estimates of the fixed effect. In Hansen et al. (2004) and Eaglen and Bijma (2009), the age effect showed a linear increase with time leading to a reduction of calving difficulties but without reaching, as in our study, a plateau level from age 5 to 9 on. But this could be because of the fact that these studies only included cows up to age 3 to 4 years, whereas our study included horse up to age 20 years. In horses, the choice of age at first foaling is a possibility. Only $3 \%$ to $9 \%$ of $A, B$ and $P$ mares foaled at age 3 years, which is the regulatory possibility and more or less the biological limit (foaling at 2 years old might be possible). The great majority of mares began their reproductive life at 4 years and there are still new mares after 6 years (B: $8 \%$ to $P: 14 \%)$. This particularity meant we were able to calculate the interaction between age and parity, and 
comfort breeders in their choice to avoid foaling before age 3 years for less difficult births.

It is interesting to go back to the very first study that tried to distinguish between heredity, environment, maternal and direct effects on the size of foals (Walton and Hammond, 1938) and comment what has been learnt since then. Most studies have focused on the mechanistic effects of the mares on foaling: McCue and Ferris (2012) and Ginther and Williams (1996) showed that abnormal foetal postures and longer stage II labour increased mortality. Gestation length is also a well-known factor: McCue and Ferris (2012) found higher SB rates for short or long gestation lengths. In a protocol similar to that of Walton and Hammond (1938), Allen et al. (2002) showed that foal weight is regulated by the mare by transferring a pony embryo into the uterus of a thoroughbred mare, and reciprocal transfer of thoroughbred embryos into pony mares. They analysed the placenta and proved that weight at birth is determined by the total microscopic area of foetomaternal contact, which is the product of the density of microcotyledons on the allantochorion, a function of the mare regardless the breed of foetus, and the volume of the allantochorion, which is determined by both the genetics of the mare and of the foal. Information of this kind was not available in our study and therefore we can only conclude on the mare or foal effect as a percentage of unexplained variance. The high direct heritability of FE (mean 0.19 ) suggests that the importance of the foal was perhaps underestimated in these previous studies. In fact, the mare provides half of the direct effect to her foal (a quarter of the variance) and the entire maternal effect with moderate negative correlation (mean -0.33 ). So the influence of the mares, added to the common environmental effect, reached $28 \%$ (mean of repeatability), whereas the sire effect is of only a quarter of the direct effect, that is, $5 \%$. The influence of the mare observed here is therefore compatible with the genetic parameters obtained.

\section{Conclusion}

This study is the first to report the estimation of the genetic parameters for dystocia and SBs in horses. The ranges of heritabilities were around the upper limits of those reported for cattle in the literature, especially for SBs. On the basis of our results, breeders should be advised to avoid mating at age 3 years and to be particularly vigilant in the busy spring months when most foals are born. The EBVs produced will provide breeders with additional information on sires. It should be noted though that we will have to wait at least 5 years before being able to provide EBVs for the maternal effect in stallions. In order to partially alleviate this problem and provide genetic information on an earlier basis, we plan to obtain information on morphological traits and expect to find a correlation between one or several morphological criteria and direct or maternal effects on dystocia.

\section{Acknowledgements}

The authors would like to thank the IFCE (Institut Français du Cheval et de l'Equitation) for providing us with the data and the breeding association of Ardennais, Breton, Comtois and Percheron.

\section{References}

Allen WR, Brown L, Wright M and Wilsher S 2007. Reproductive efficiency of flatrace and national hunt thoroughbred mares and stallions in England. Equine Veterinary Journal 39, 438-445.

Allen WR, Wilsher S, Turnbull C, Stewart F, Ousey J, Rossdale PD and Fowden AL 2002. Influence of maternal size on placental, fetal and postnatal growth in the horse. I. Development in utero. Reproduction 123, 445-453.

Carnier P, Albera A, Dal Zotto R, Groen AF, Bona M and Bittante G 2000. Genetic parameters for direct and maternal calving ability over parities in Piedmontese cattle. Journal of Animal Science 78, 2532-2539.

Eaglen SAE and Bijma P 2009. Genetic parameters of direct and maternal effects for calving ease in Dutch Holstein-Friesian cattle. Journal of Dairy Science 92, 2229-2237.

Eaglen SAE, Coffey MP, Woolliams JA and Wall E 2012. Evaluating alternate models to estimate genetic parameters of calving traits in United Kingdom Holstein-Friesian dairy cattle. Genetics Selection Evolution 44, 23.

Ginther OJ and Williams D 1996. On-the-farm incidence and nature of equine dystocias. Journal of Equine Veterinary Science 16, 159-164.

Hansen M, Lund MS, Pedersen J and Christensen LG 2004. Gestation length in Danish Holsteins has weak genetic associations with stillbirth, calving difficulty, and calf size. Livestock Production Science 91, 23-33.

Jamrozik J, Fatehi J, Kistemaker GJ and Schaeffer LR 2005. Estimates of genetic parameters for Canadian Holstein female reproduction traits. Journal of Dairy Science 88, 2199-2208.

Johanson JM, Berger PJ, Tsuruta S and Misztal I 2011. A Bayesian thresholdlinear model evaluation of perinatal mortality, dystocia, birth weight, and gestation length in a Holstein herd. Journal of Dairy Science 94, 450-460.

Langlois B, Blouin C and Chaffaux S 2012. Analysis of several factors of variation of gestation loss in breeding mares. Animal 6, 1925-1930.

Legarra A, Varona L and Lopez de Maturana E 2011. TM Threshold Model. Retrieved April 22, 2013, from http://snp.toulouse.inra.fr/ alegarra.

Leroy G, Callede L, Verrier E, Meriaux JC, Ricard A, Danchin-Burge C and Rognon X 2009. Genetic diversity of a large set of horse breeds raised in France assessed by microsatellite polymorphism. Genetics, Selection, Evolution 41,5 .

Lopez de Maturana E, Legarra A, Varona L and Ugarte E 2007. Analysis of fertility and dystocia in Holsteins using recursive models to handle censored and categorical data. Journal of Dairy Science 90, 2012-2024.

Lopez de Maturana E, Gianola D, Rosa GJM and Weigel KA 2009a. Predictive ability of models for calving difficulty in US Holsteins. Journal of Animal Breeding and Genetics 126, 179-188.

Lopez de Maturana E, Wu XL, Gianola D, Weigel KA and Rosa GJM 2009b. Exploring biological relationships between calving traits in primiparous cattle with a Bayesian recursive model. Genetics 181, 277-287.

Luo MF, Boettcher PJ, Schaeffer LR and Dekkers JCM 2002. Estimation of genetic parameters of calving ease in first and second parities of Canadian Holstein-Friesians using Bayesian methods. Livestock Production Science 74, 175-184.

McCue PM and Ferris RA 2012. Parturition, dystocia and foal survival: a retrospective study of 1047 births. Equine Veterinary Journal 41, 22-25. (vol. 45, p. 259, 2013).

Meyer CL, Berger PJ and Koehler KJ 2000. Interactions among factors affecting stillbirths in Holstein cattle in the United States. Journal of Dairy Science 83, 2657-2663.

Meyer CL, Berger PJ, Thompson JR and Sattler CG 2001a. Genetic evaluation of Holstein sires and maternal grandsires in the United States for perinatal survival. Journal of Dairy Science 84, 1246-1254.

Meyer CL, Berger PJ, Koehler KJ, Thompson JR and Sattler CG 2001b. Phenotypic trends in incidence of stillbirth for Holsteins in the United States. Journal of Dairy Science 84, 515-523.

Moreno C, Sorensen D, GarciaCortes LA, Varona L and Altarriba J 1997. On biased inferences about variance components in the binary threshold model. Genetics Selection Evolution 29, 145-160. 
Phocas F and Laloe D 2003. Evaluation models and genetic parameters for calving difficulty in beef cattle. Journal of Animal Science 81, 933-938.

Phocas F and Laloe D 2004. Genetic parameters for birth and weaning traits in French specialized beef cattle breeds. Livestock Production Science 89, 121-128.

Sorensen D and Gianola D 2002. Likelihood, Bayesian and MCMC methods in quantitative genetics. Springer-Verlag, New York, USA.

Squires EL, Hughes SE, Ball BA, Troedsson MHT and Stowe J 2013. Effect of season and reproductive status on the incidence of equine dystocia. Journal of Equine Veterinary Science 33, 375.

Steinbock L, Nasholm A, Berglund B, Johansson K and Philipsson J 2003. Genetic effects on stillbirth and calving difficulty in Swedish Holsteins at first and second calving. Journal of Dairy Science 86, 2228-2235.
Steinbock L, Johansson K, Nasholm A, Berglund B and Philipsson J 2006. Genetic effects on stillbirth and calving difficulty in Swedish Red dairy cattle at first and second calving. Acta Agriculturae Scandinavica Section A-Animal Science 56, 65-72.

Varona L, Misztal I and Bertrand JK 1999. Threshold-linear versus linear-linear analysis of birth weight and calving ease using an animal model: I. Variance component estimation. Journal of Animal Science 77, 1994-2002.

Walton A and Hammond J 1938. The maternal effects on growth and conformation in Shire horse-Shetland pony crosses. Proceeding of the Royal Society of London, Series B 125, 311-335.

Wiggans GR, Misztal I and Tassell CPv 2003. Calving ease (co)variance components for a sire-maternal grandsire threshold model. Journal of Dairy Science $86,1845-1848$ 